\title{
Article \\ Biostimulation of Anaerobic Digestion Using Iron Oxide Nanoparticles (IONPs) for Increasing Biogas Production from Cattle Manure
}

\author{
Dilbag Singh ${ }^{1}$, Kamla Malik ${ }^{1, *}$, Meena Sindhu ${ }^{1}$, Nisha Kumari ${ }^{2}{ }^{\circledR}$, Vijaya Rani ${ }^{3}$, Shikha Mehta ${ }^{1}$, \\ Karmal Malik ${ }^{4}$, Poonam Ranga ${ }^{1}$, Kashish Sharma ${ }^{1}$, Neeru Dhull ${ }^{1}$, Shweta Malik ${ }^{4}$ and Nisha Arya ${ }^{5}$
}

1 Department of Microbiology, CCS Haryana Agricultural University, Hisar 125004, India; sdilbag460@gmail.com (D.S.); meenasindhu20@gmail.com (M.S.); shikhamicrobio@gmail.com (S.M.); rangamicro@yahoo.co.in (P.R.); kashishsharma7000@gmail.com (K.S.); dhullneeru11@gmail.com (N.D.)

2 Department of Biochemistry, CCS Haryana Agricultural University, Hisar 125004, India; nishaahlawat211@gmail.com

3 Department of Farm Machinery and Power Engineering, CCS Haryana Agricultural University, Hisar 125004, India; vijayarani@yahoo.com

4 Department of Agronomy, CCS Haryana Agricultural University, Hisar 125004, India; karmalsingh@gmail.com (K.M.); malik.shweta54@gmail.com (S.M.)

5 Department of Textile and Apparel Designing, CCS Haryana Agricultural University, Hisar 125004, India; nishasangwan@gmail.com

* Correspondence: kamlamalik06@gmail.com; Tel.: +91-941-634-6472

check for updates

Citation: Singh, D.; Malik, K.; Sindhu, M.; Kumari, N.; Rani, V.; Mehta, S.; Malik, K.; Ranga, P.; Sharma, K.; Dhull, N.; et al. Biostimulation of Anaerobic Digestion Using Iron Oxide Nanoparticles (IONPs) for Increasing Biogas Production from Cattle Manure. Nanomaterials 2022, 12, 497. https://doi.org/10.3390/ nano12030497

Academic Editors: Irfan Anjum Badruddin Magami and Alexey Pestryakov

Received: 29 December 2021

Accepted: 25 January 2022

Published: 31 January 2022

Publisher's Note: MDPI stays neutral with regard to jurisdictional claims in published maps and institutional affiliations.

Copyright: (C) 2022 by the authors. Licensee MDPI, Basel, Switzerland. This article is an open access article distributed under the terms and conditions of the Creative Commons Attribution (CC BY) license (https:// creativecommons.org/licenses/by/ $4.0 /)$.

\begin{abstract}
The effect of synthesised IONPs employing a nontoxic leaf extract of Azadirachta indica as a reducing, capping, and stabilizing agent for increasing biogas and methane output from cattle manure during anaerobic digestion (AD) was investigated in this study. Furthermore, the UV-visible spectra examination of the synthesized nanoparticles revealed a high peak at $432 \mathrm{~nm}$. Using a transmission electron microscope, the average particle size of IONPs observed was $30-80 \mathrm{~nm}$, with irregular, ultra-small, semi-spherical shapes that were slightly aggregated and well-distributed. IONPs had a polydisparity index (PDI) of $219 \mathrm{~nm}$ and a zeta potential of $-27.0 \mathrm{mV}$. A set of six bio-digesters were fabricated and tested to see how varying concentrations of IONPs $(9,12,15$, 18 , and $21 \mathrm{mg} / \mathrm{L}$ ) influenced biogas, methane output, and effluent chemical composition from $\mathrm{AD}$ at mesophilic temperatures $\left(35 \pm 2{ }^{\circ} \mathrm{C}\right)$. With $18 \mathrm{mg} / \mathrm{L} \mathrm{IONPs,} \mathrm{the} \mathrm{maximum} \mathrm{specific} \mathrm{biogas} \mathrm{and}$ methane production were $136.74 \mathrm{~L} / \mathrm{g}$ of volatile solids (VS) and $64.5 \%$, respectively, compared to the control $(p<0.05)$, which provided only $107.09 \mathrm{~L} / \mathrm{g}$ and $51.4 \%$, respectively. Biogas and methane production increased by $27.6 \%$ and $25.4 \%$, respectively using $18 \mathrm{mg} / \mathrm{L}$ IONPs as compared to control. In all treatments, the $\mathrm{pH}$ of the effluent was increased, while total volatile fatty acids, total solids, volatile solids, organic carbon content, and dehydrogenase activity decreased. Total solid degradation was highest $(43.1 \%)$ in cattle manure $+18 \mathrm{mg} / \mathrm{L}$ IONPs (T5). According to the results, the IONPs enhanced the yield of biogas and methane when compared with controls.
\end{abstract}

Keywords: biogas production; anaerobic digestion; methane; cattle manure; iron oxide nanoparticles; Azadirachta indica

\section{Introduction}

Biogas production is a well-established bioconversion technology (anaerobic digestion) for obtaining energy from biomass, which is a potent, renewable, and eco-friendly fuel [1]. One of the most important processes for transforming organic waste into valuable products and renewable energy in the form of methane, carbon dioxide, and other trace elements is anaerobic digestion [2,3]. With benefits such as reduced organic pollution, energy recovery, and low operating costs, anaerobic digestion (AD) has become a popular approach for recycling organic wastes into energy [4]. The use of additives in the anaerobic 
digestion process has further enhanced biogas output. Recent studies have revealed that the addition of nanoparticles has been found to affect the anaerobic digestion process and enhance biogas. The fundamental process of methane production is behind the interspecies electron transfer (IET) mechanism [5]. In this context, green nanotechnology, which is grabbing the attention of the biofuels and bioenergy sectors by playing the role of enhancer, improves production technology. Nanoparticles synthesised using green technology are preferred because of their low cost and similar processing characteristics to other metallic nanoparticles [6]. Nanotechnology's contributions to catalysts, enzymes, and microbial immobilization are a novel sector for biofuel and bioenergy production [7]. Due to current sustainability concerns, research on eco-friendly and green synthesis for the development of nanoparticles based on plant extracts has gained a lot of attention. Finally, biological materials (plants) can be synthesized cheaply and thus can function as reducing and capping agents [8,9]. The common plant neem (Azadirachta indica) is a member of the Meliaceae family and is plentiful in India. According to the literature [10-12], the major active phytochemicals of Azadirachta indica are azadirachtin, nimbin [13], nimbolinin, nimbidin [14], quercetin, gedunin [15], salannin, ascorbic acid, and amino acids [16]. The fresh leaf extract of neem also contains various active biological compounds such as terpenoids, sitosterol, polyphenolic flavonoids, saponins, and alkaloids that act as reducing and capping agents and aid in the stabilization of nanoparticles [10]. As a result, there is a rising need to develop nanoparticle synthesis techniques that are clean, non-toxic, and ecologically benign. There is still scope for progress in terms of inventive techniques to improve the biogas production system's efficiency, productivity, and long-term viability. As examined and discussed by Meegoda et al. [1] and Tabatabaei et al. [17], anaerobic digestion is the main biological advancement for improving the biogas production process but further research is needed to increase the efficiency and reduce the associated cost and time. Therefore, it is critical to create green technologies for nanoparticle synthesis that are less harmful to human health and the environment. Recent studies have found that various types of IONPs increase the AD process [18,19] and the methane fraction in biogas [20,21]. In comparison to control, the addition of iron nanoparticles as an additive or catalyst to a co-digestion system significantly increased biogas output while lowering chemical oxygen consumption and stimulating microbial activity [22]. Despite the fact that scientists have attempted to produce biogas from a variety of lignocellulosic plant materials, few studies have been carried out to enhance biogas production using plant-derived nanoparticles. As a result, the influence of successfully synthesised and characterized IONPs on biogas generation, methane yield, and chemical composition during the anaerobic processes of cattle manure has been investigated.

\section{Materials and Methods}

\subsection{Experimental Materials}

The cattle manure was collected from the dairy farm of Lala Lajpat Rai University of Veterinary and Animal Sciences, Hisar, India. The main characteristics of the cattle manure, i.e., $\mathrm{pH}$, TS, VS, TVFA, Organic carbon, Nitrogen, Carbon Nitrogen ratio, were analysed with the following analytical methods:

- Determination of $\mathrm{pH}$ : The $\mathrm{pH}$ of the cattle dung, the influents, and the effluents was determined using an Elico pH meter (Elico ltd., Hyderabad, India) and was 6.17.

- Determination of Total Solids (TS): $100 \mathrm{~g}$ sample was dried at $80{ }^{\circ} \mathrm{C}$ to a constant weight for determination of total solids. The residue left was weighed and taken as total solids. We arrived at a figure of $18.42 \%$ TS.

- $\quad$ Determination of Volatile Solids (VS): $1.0 \mathrm{~g}$ of fine dried powder sample was taken in a pre-weighed china crucible and incinerated in a muffle furnace at $550{ }^{\circ} \mathrm{C}$ for $1 \mathrm{~h}$. The loss in weight of TS (total solids) to combustion was taken as volatile solids, which was found to be $82.0 \%$. 
- Determination of Organic Carbon Content: Organic carbon content of the samples was calculated as:

$$
\% \mathrm{C}=\frac{\% \text { Volatile Solids }}{1.724}
$$

Organic carbon was found to be $47.16 \%$.

- Determination of cellulose, hemicellulose, and lignin: Cellulose, lignin, and hemicellulose contents were estimated by determining acid detergent fibre (ADF) and neutral detergent fibre (NDF) in the sample powder (AOAC, 2000) and were found to be 39.2, 16.5 , and $11.82 \%$, respectively.

- TVFA, Nitrogen, and $\mathrm{C} / \mathrm{N}$ were analysed using standard protocols and were found to be $695 \mathrm{mg} / \mathrm{kg}, 1.32 \%(\mathrm{~N})$ and $20.1(\mathrm{C} / \mathrm{N})$, respectively.

\subsection{Chemicals}

In this study, all the chemicals used were AR and GR grade (Sigma Aldrich, St. Louis, MO, USA and Himedia laboratories pvt. Ltd., Mumbai, India) and thus they did not need to be purified further.

\subsection{Preparation of Neem (Azadirachta Indica) Leaves Extract}

Young and healthy leaves of neem were collected from the Chaudhary Charan Singh Haryana Agricultural University campus, Hisar, India. The leaves were washed thoroughly with distilled water to eliminate dust particles and then the air dried at room temperature. The leaves were cut into small pieces and grind into a fine powder. In a conical flask, $5.0 \mathrm{~g}$ of finely ground neem leaf powder was added to $100 \mathrm{~mL}$ of sterile distilled water and boiled for $10 \mathrm{~min}$ at $80^{\circ} \mathrm{C}$. Then, the extracts were filtered twice through Whatman filter paper No. 1 to remove particulate matter and centrifuged at $5000 \mathrm{rpm}$ for $5 \mathrm{~min}$ [11]. The green, clear filtered solution of neem leaf extract was stored at $4{ }^{\circ} \mathrm{C}$ for further use. Initially, the TS, VS, and total phenolics of neem leaf were $17.01 \%, 92.30 \%$, and $27.02(\mathrm{mg} / \mathrm{g})$, respectively.

\subsection{Biosynthesis of IONP}

IONP nanoparticles were synthesized utilizing neem (Azadirachta indica) leaf extract as the green reducing agent using modified protocols [23,24]. Neem leaf extract and iron (III) chloride hexahydrate $\left(\mathrm{FeCl}_{3} \cdot 6 \mathrm{H}_{2} \mathrm{O}\right)$ solution $(0.03 \mathrm{M})$ were dissolved in $100 \mathrm{~mL}$ of sterile deionized water at a 1:1 ratio in a procedure. The resulting mixture was heated at $80{ }^{\circ} \mathrm{C}$ for $20 \mathrm{~min}$, stirring occasionally with a magnetic stirrer, until the pale yellow colour became brownish black. The appearance of an instantaneous black colour indicated the synthesis of IONPs, and the reaction mixture was then allowed to cool to room temperature. A decrease in the $\mathrm{pH}$ of the solution was also observed, indicating the synthesis of IONPs. The solution was poured into a beaker after $30 \mathrm{~min}$ and the supernatant was discarded by magnetic decantation. The black precipitates of IONPs were again washed with $20 \mathrm{~mL}$ of distilled water after centrifugation at $10,000 \mathrm{rpm}$ for $15 \mathrm{~min}$. The supernatant was removed once again. The pellet was transferred to a vial and $10 \mathrm{~mL}$ of ethanol was added to remove excess phytochemicals and supernatant. After we obtained the black powder, it was freeze-dried overnight and used for further characterization.

\subsection{Characterization of IONPS}

A UV-visible Eppendorf Bio spectrometer (Systronics, Ahmadabad, India) between 300 and $700 \mathrm{~nm}$ with a resolution of $1.0 \mathrm{~nm}$ was used to characterize effectively produced IONPs. The particle size of the IONPs was determined using a laser light scattering nanosize particle analyser and a zeta sizer Nano ZS-90 (Malvern Instruments, Cambridge, UK). Transmission electron microscope (Hitachi H-7650-80 KV, Leipzig, Germany) scanning at $100 \mathrm{kV}$ was used to characterize the size and shape of the synthesized IONPs. Drop deposition onto a carbon/formvar coated copper grid yielded approximately 10-20 L of samples, which were air dried before imaging with a microscope. 


\subsection{Experimental Setup}

The experiments were performed to evaluate the effects of different concentrations of synthesized and characterized IONPs on biogas and methane content during the AD of cattle manure (Table 1 ).

Table 1. Bio-digesters with different concentrations of IONPs for biogas production.

\begin{tabular}{cc}
\hline Treatments & Description \\
\hline T1 & Cattle manure (Control) \\
T2 & Cattle manure $+9 \mathrm{mg} / \mathrm{L} \mathrm{IONPs}$ \\
T3 & Cattle manure $+12 \mathrm{mg} / \mathrm{L} \mathrm{IONPs}$ \\
T4 & Cattle manure $+15 \mathrm{mg} / \mathrm{L} \mathrm{IONPs}$ \\
T5 & Cattle manure $+18 \mathrm{mg} / \mathrm{L} \mathrm{IONPs}$ \\
T6 & Cattle manure $+21 \mathrm{mg} / \mathrm{L} \mathrm{IONPs}$ \\
\hline
\end{tabular}

Six laboratory scale batch experiments were set up with the capacity of 5 litre glass bottle digesters fed with cattle manure $(3 \mathrm{~kg})$ and IONPs at $35 \pm 2{ }^{\circ} \mathrm{C}$ (Figure 1 ).

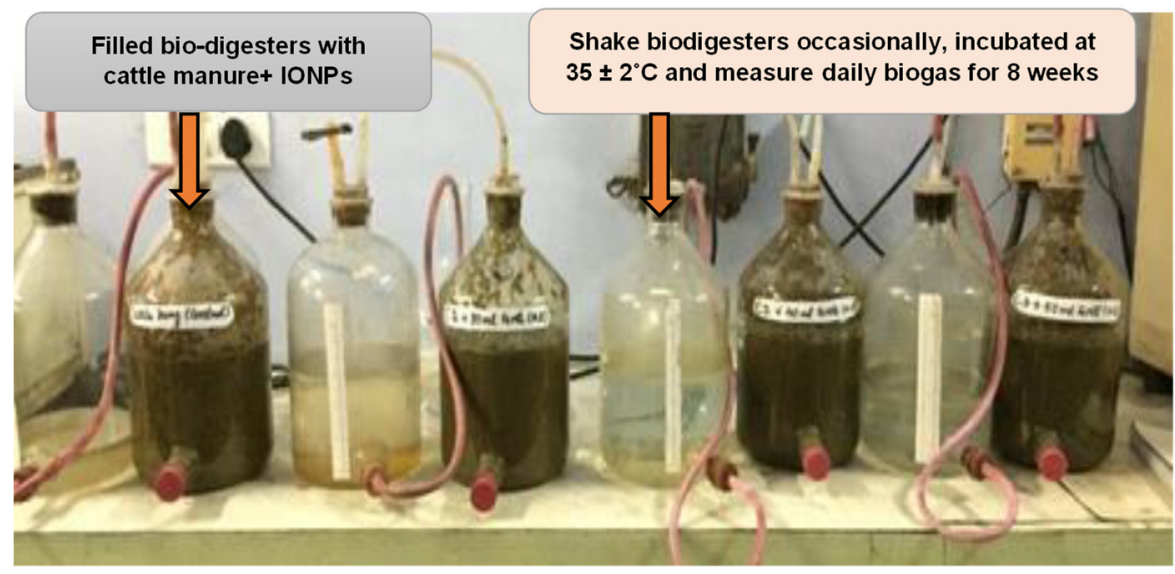

Figure 1. Schematic diagram of a laboratory-scale biodigester experimental setup for biogas production.

The IONPs were ultrasonically treated in deionized water for $7 \mathrm{~min}$ prior to being added to batch type AD to prevent aggregation and increase their stability. Six glass bottles were flushed with nitrogen flow and sealed with a butyl rubber stopper to establish anaerobic conditions. The gas collecting bottle was filled with water and the gas produced in the digester displaced water in the collecting bottle, which helped with the quantitative analysis of biogas. The sampling was conducted using a syringe at different time intervals for $\mathrm{pH}, \mathrm{TS}, \mathrm{VS}, \mathrm{OC}$, and TVFA using standard methods [25]. The samples were also analysed for dehydrogenase activity as described by Casida et al. [26]. The biogas was collected in graduated test tubes and its volume was measured based on the water displacement method. Methane content was estimated by a portable biogas analyser for eight weeks of digestion.

\subsection{Statistical Analysis}

All tests were performed in triplicate, and the significance of the results was determined using analyses of variance (ANOVAs). Statistical significance was defined as $p<0.05$.

\section{Results and Discussion}

\subsection{Biosynthesis of IONPS}

The aqueous solution of neem leaf extract was mixed with iron (III) chloride hexahydrate $\left(\mathrm{FeCl}_{3} \cdot 6 \mathrm{H}_{2} \mathrm{O}\right)$ solution. The precursors' colour changed from pale yellow to light orange, then black, and the $\mathrm{pH}$ dropped from 6.50 to 2.59. (Figure 2). It was observed 
that the instantaneous black colour change takes approximately 30 min and after that no change in the reaction mixture's colour was observed. The results were in agreement with Christensen et al. [27], where the colour changed from a slight yellowish to brown and finally to black. After $24 \mathrm{~h}$, there was no more change in colour in the reaction mixture. This indicated that all the iron salts in the reaction solution had been completely reduced. The presence of IONPs synthesized by the reduction of iron salts led to the colour and $\mathrm{pH}$ of the solution changing. It was proposed that neem leaf extract acts as a reducing agent due to the presence of compounds like terpenoids and flavanones [28].

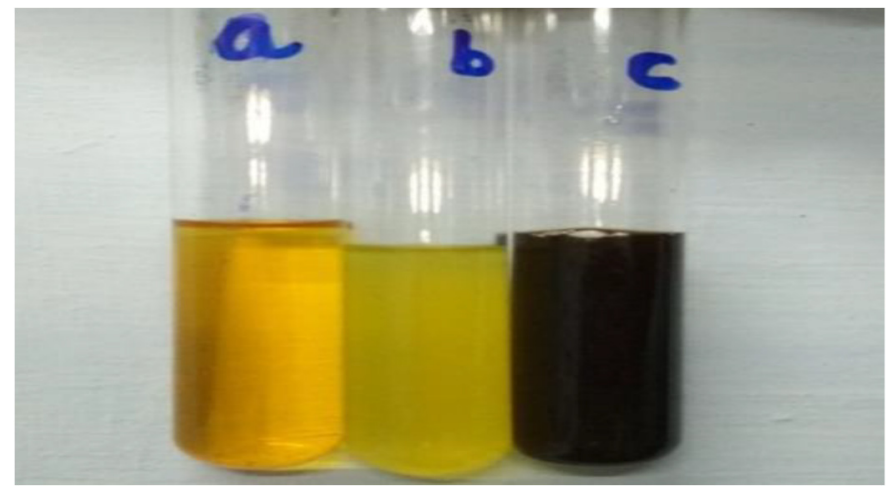

Figure 2. Synthesis of IONPs using Azadirachta indica (a-ferric chloride aqueous solution; $\mathrm{b}$ - neem leaf extract; c-synthesized IONPs).

\subsection{Characterization of IONPS}

A UV-Vis spectral analysis was used to confirm the formation and stability of IONPs in aqueous solution (Figure 3). The excitation of molecules by surface plasmon vibrations in IONPs was attributed to the presence of a significant peak at $432 \mathrm{~nm}$. Devatha et al. [29] found identical UV-VIS spectra for synthesised $\mathrm{Fe}_{3} \mathrm{O}_{4} \mathrm{NPs}$ in their studies. Precipitated magnetite nanoparticles take on colour as a result of molecular excitation produced by surface plasmon resonance (SPR). Effective absorption occurs when the frequency of the electromagnetic field remains coherent with the electric motion. Aqueous colloidal solution has been used to confirm the synthesis and stability of IONPs. The maximum absorbance was read at $229 \mathrm{~nm}$. There was no more absorption after $500 \mathrm{~nm}$, resulting in a reduction and the formation of IONPs. A characteristic surface plasmon resonance band for IONPs was observed at a wavelength of 190-250 nm [30].

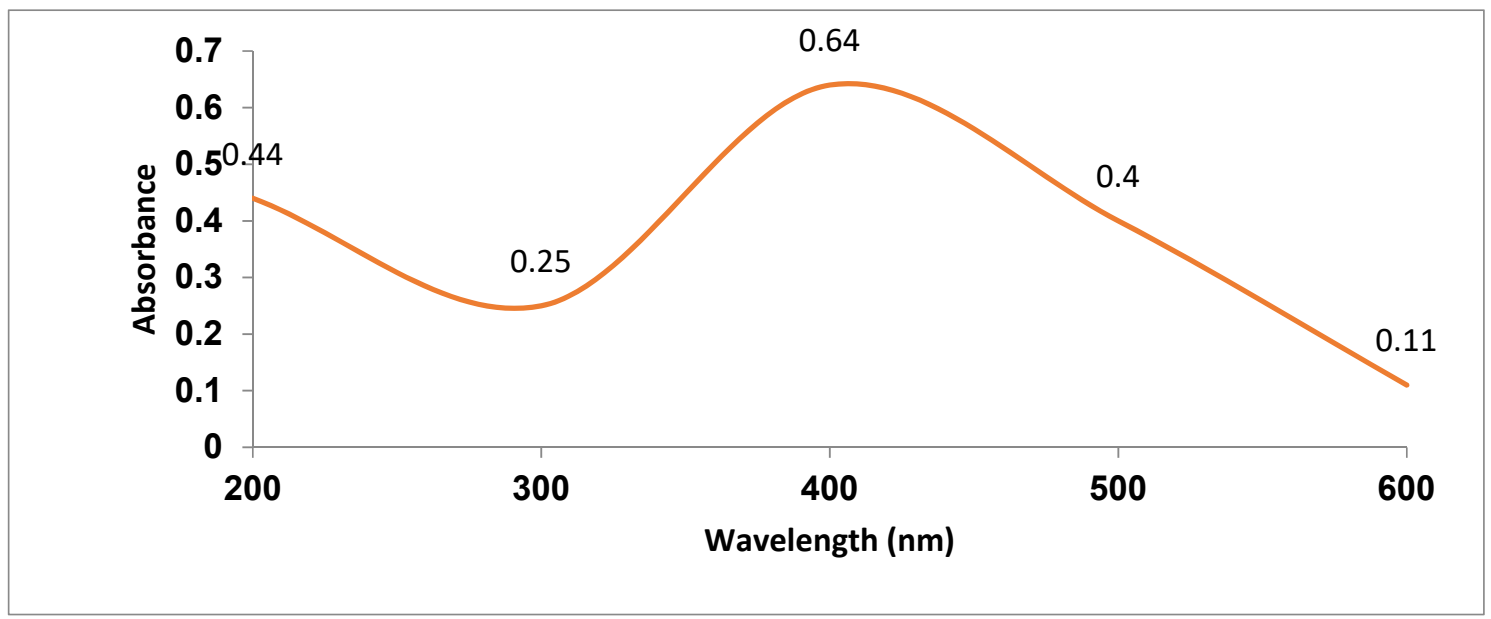

Figure 3. UV-visible absorption spectra of IONPs.

Turakhia et al. [31] reported identical UV-visible spectra for green synthesis of IONPs from Spinacia oleracea with a peak at $404 \mathrm{~nm}$. The absorption spectrum of IONPs was 
observed at $371.71 \mathrm{~nm}$ when prepared via the green route using Pomegranate granatum seeds [23]. During this study, the IONPs were synthesized in 30 min using a green process involving non-toxic neem leaves, making this method suitable for practical application. Furthermore, a particle size analyser (PSA) was used to measure the size of IONPs and the polydispersity indexes (PDI) were observed to be $219 \mathrm{~nm}$ (Figure 4). The average particle size and the polydispersity index (PDI) indicate the qualities most closely related to the size distribution of nanoparticles.

Size Distribution by Intensity

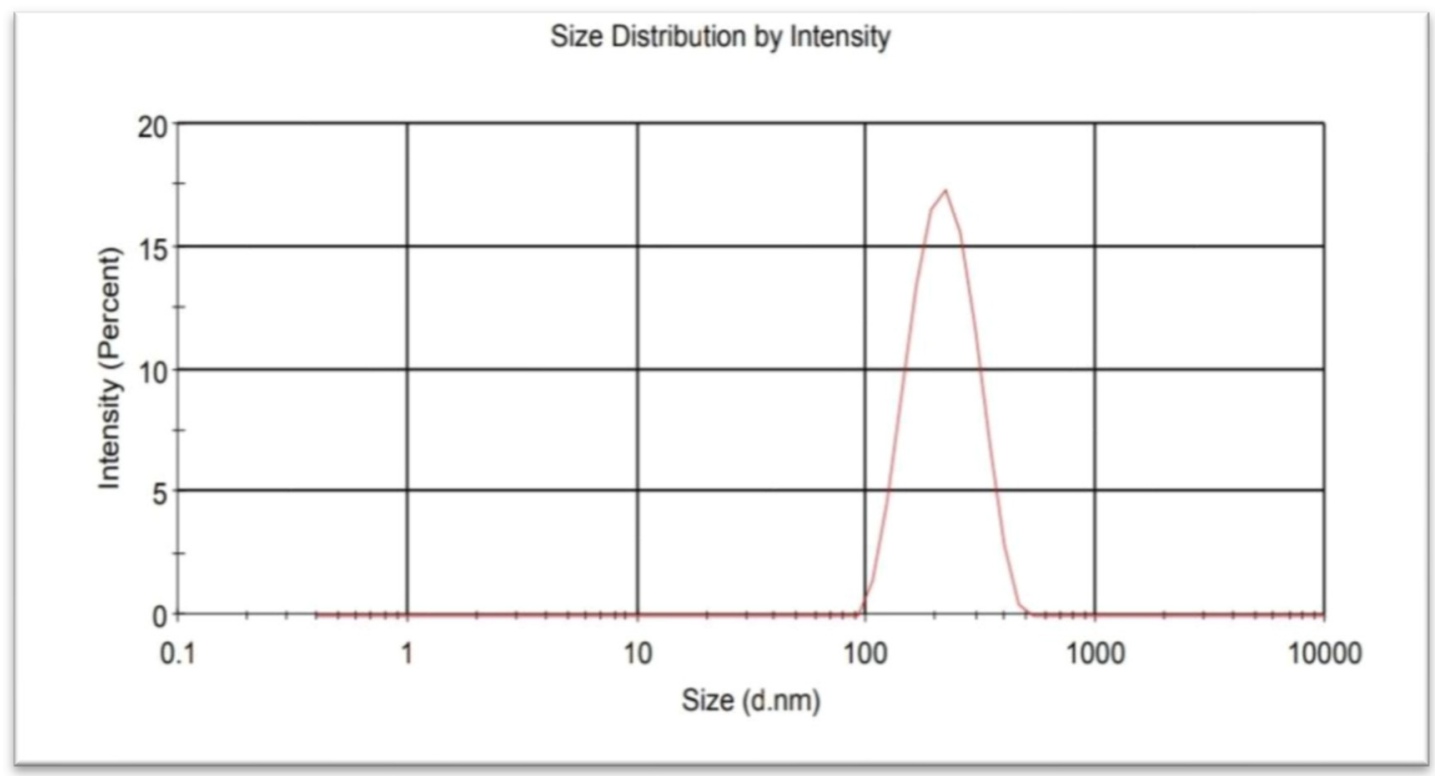

Figure 4. PSA of synthesized IONPs from neem leaf extract.

The zeta potential (surface potential) has a direct relationship with the stability of nanoparticles and was $-27.0 \mathrm{mV}$ (Figure 5), indicating the good stability of the synthesised IONPs. Furthermore, the synthesized IONPs maintained their stability one month after synthesis. Due to the electrostatic repulsion of individual particles, a positive or negative zeta potential of nanoparticles indicates the strong physical stability of nanosuspensions. A zeta potential beyond the range of $-30 \mathrm{mV}$ to $+30 \mathrm{mV}$ is generally thought to have adequate repulsive force to achieve better physical colloidal stability. Due to the van der Waals attractive forces acting on nanoparticles, a small zeta potential value can cause particle aggregation and flocculation. It was observed that the zeta potential of IONPs with values of $>+25 \mathrm{mV}$ or $25 \mathrm{mV}$ usually has a high degree of stability. Low dispersion ZP values will lead to aggregation, coagulation, or flocculation due to van der Waals interparticle attraction. The zeta potential is one of the key properties of the particle that can affect particle stability as well as its cell adhesion. Particle suspensions with positive or negative zeta potentials have a significant role in stabilizing them. This is attributed to the electrostatic repulsion between particles with the same electric charge that causes the segregation of particles [32].

TEM at $80 \mathrm{kV}$ in high contrast imaging mode was used to examine the size, shape, and structure of the synthesized IONPs. Figure 6 shows TEM images taken from the drop coated grids of IONPs. It was observed that the synthesized IONPs were mostly irregular in shape and particle size, with some variations ranging from 30 to $80 \mathrm{~nm}$, while the average mean particle size was around $52.5 \mathrm{~nm}$.

Similar results for IONPs were investigated by Machado et al. [8] and Mystrioti et al. [33] using pomegranate, mulberry, and cherry leaf extracts. The average diameter of NPs was found to be $21.59 \mathrm{~nm}$ after 100 particles were selected to determine their size. The large, agglomerated clusters were formed on the basis of the accumulation of tiny building blocks of various bioactive reducing agents in the plant extract or as a result of the plant extract's lower capping ability and the tendency of iron-based nanoparticles to agglomerate due to 
magnetic interactions. The IONPs were deeply surrounded by biological components from the neem leaf extract. Therefore, the resulting structure was a microstructure composed of IONPs and phytochemical compounds.

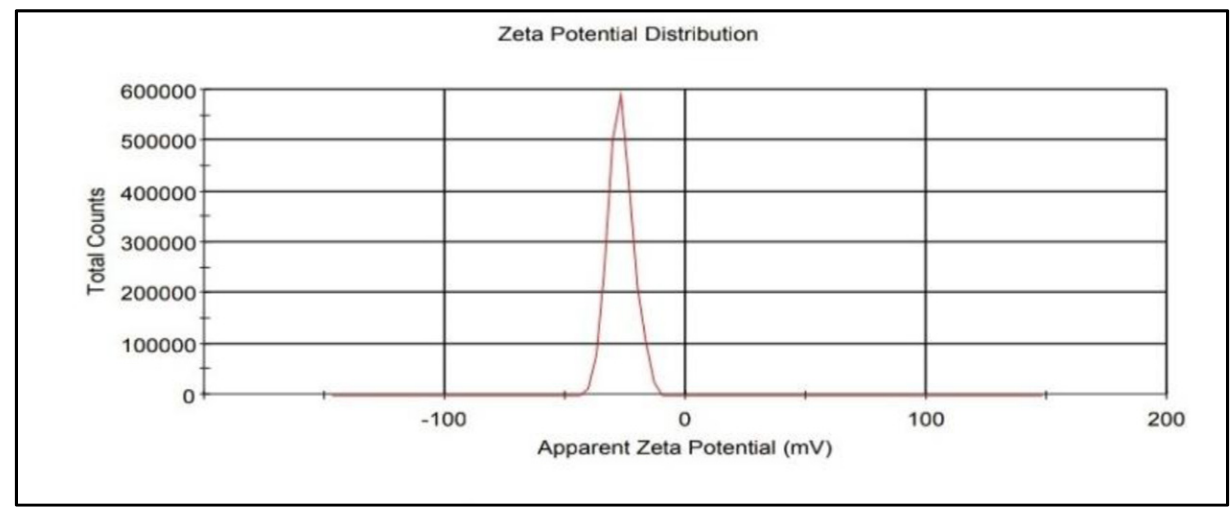

Figure 5. Determining the zeta potential of IONPs.

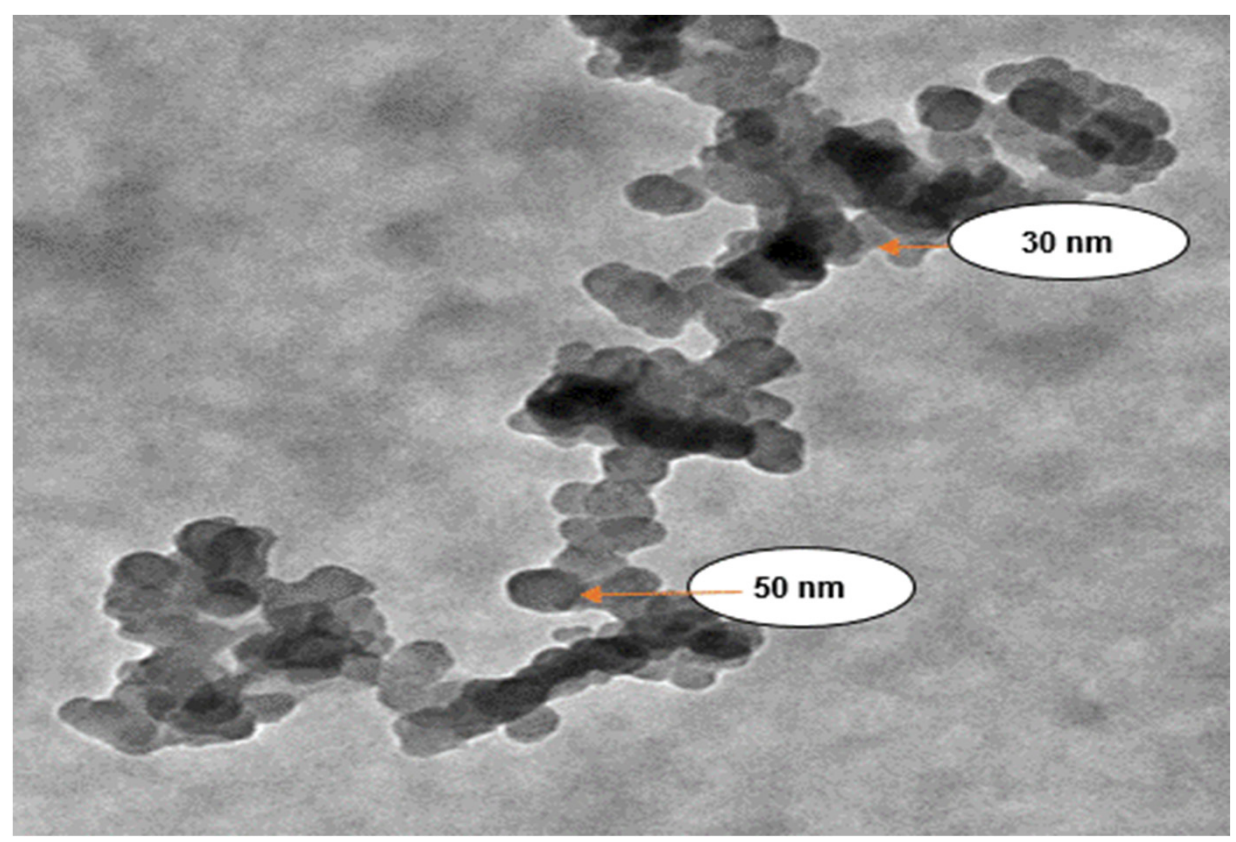

Figure 6. A TEM micrograph of synthesized IONPs.

\subsection{Effect of IONPs on Anaerobic Digestion (AD) of Cattle Manure}

During eight weeks of digestion, biogas and supernatant were measured daily to analyse the effect of IONPs on the AD of cattle manure until the biogas production stopped. Figure 7 shows the changes in accumulative biogas production. Six biodigesters started to produce biogas rapidly after the second week of digestion, and biogas yield increased by $27.6 \%$ in T5 compared to control (T1) after the fifth week. Compared with control (T1), IONPs increased biogas production in the initial stage but steadily decreased later on. T5 (18 mg/L) significantly increased accumulative biogas (29.48 L/g VS), followed by T6 (26.58 L/g VS) and T4 (25.0 L/g VS) compared with T1 (control), which was $22.91 \mathrm{~L} / \mathrm{g}$ VS. 


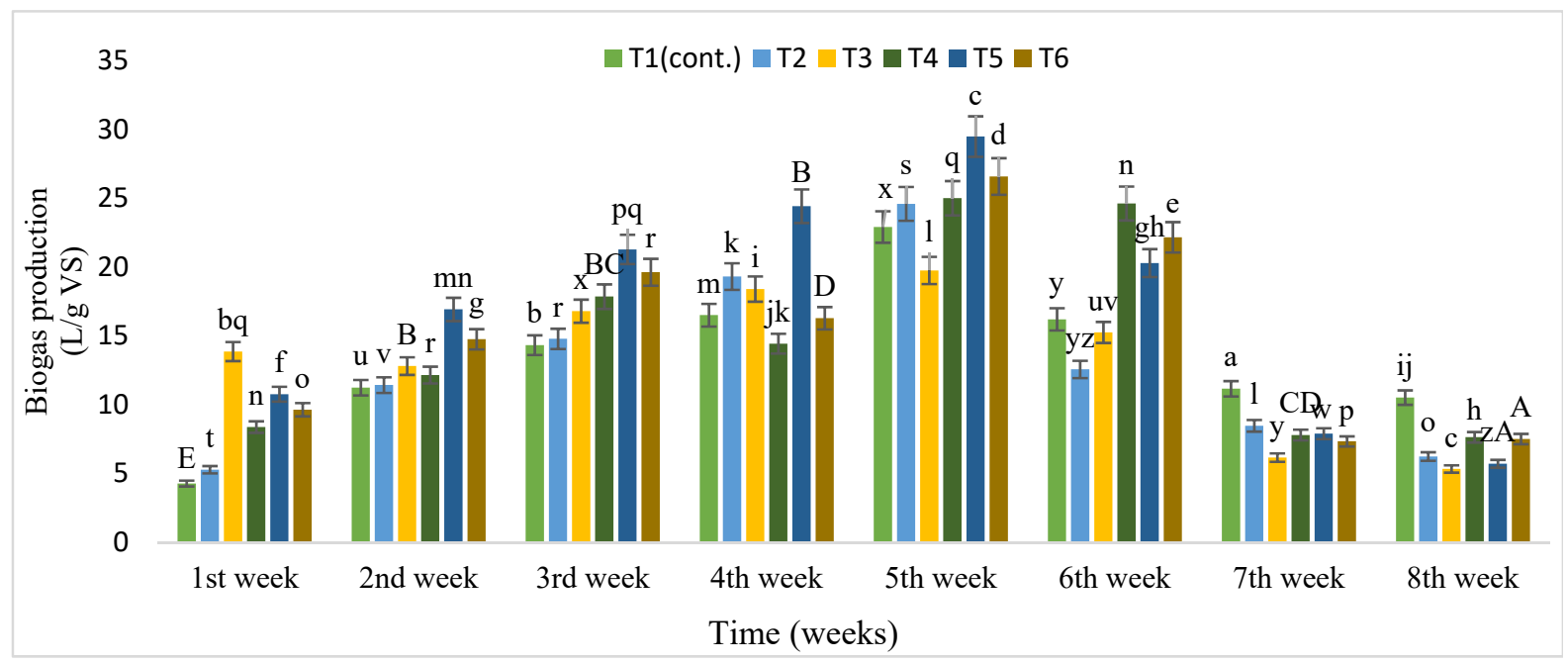

Figure 7. Biogas production (L/g of VS) from cattle manure with different concentrations of IONPs under batch digestion. Bars with different letters indicate significantly different values at $p \leq 0.05$.

The cumulative production of biogas recorded during anaerobic digestion is shown in Figure 8. The results show that the addition of IONPs in all concentrations enhanced the biogas production and shortened the lag phase. The cumulative production of biogas was found to be 136.74, 123.85, 117.83, 108.32, 102.62, and 107.09 1/g VS in the treatments T5, T6, T4, T3, and T1, respectively, after the eighth week of digestion. Similarly, the accumulative methane yield was highest in T5, i.e., $64.5 \%$ while that of the control was $51.4 \%$. There was an increase in biogas $(27.6 \%)$ and methane $(25.4 \%)$ production as compared to control after eight weeks of batch anaerobic digestion in $\mathrm{T} 5$ at the laboratory scale. The highest biogas yield was obtained from $18 \mathrm{mg} / \mathrm{L}$ of IONPs, which corresponds to up to a $27.6 \%$ enhancement over the control bioreactor. Moreover, IONPs improved COD reduction efficiency to $42 \%$ [34]. According to Feng et al. [2], adding zerovalent iron (ZVI) accelerated the anaerobic digestion of sludge, increasing biogas and methane production. Methane production was boosted by increasing the ZVI dosage up to $20 \mathrm{~g} / \mathrm{L}$ as compared to control, implying that these IONPs effectively stimulate microorganisms. The increases could have been attributed to the effect of IONPs in syntrophic/cooperative metabolism between electron-donating and electron-accepting microorganisms via direct interspecies electron transfer processes [35,36]. Yu et al. [37] studied the effect of zero valent iron (ZVI) on the anaerobic digestion of cow manure. With the addition of $10 \mathrm{~g} / \mathrm{L} \mathrm{ZVI}$, the cumulative methane and VFA yields decreased by $10.3 \%$ and $12 \%$, respectively. Previous research has shown that enhancing the performance of an anaerobic digester by adding zero-valent iron (ZVI) can boost the methane generation and degradation rate of organic wastes. The highest biogas production $\left(400 \mathrm{~mL} /\right.$ day) and methane yield $\left(100 \% \mathrm{CH}_{4}\right)$ were attained with $2 \mathrm{~g}$ of $\mathrm{Fe}_{2} \mathrm{O}_{4}-\mathrm{TiO}_{2} \mathrm{MNPs}$ as compared to the control biogas production ( $350 \mathrm{~mL} /$ day) and methane yield $\left(65 \% \mathrm{CH}_{4}\right)$ from waste water [38]. IONPs improved the methanogenic process of cattle manure in the first few weeks, but they decreased biogas and methane yield in the following days due to the proliferation of slowly growing methanogenic bacteria and inhibition caused by decaying methanogenic bacteria.

Many nanoparticles (NPs) have been reported to improve biogas production from organic waste via anaerobic digestion (AD). However, the impact of IONPs on the stability of the AD process of cattle manure and the chemical composition of the effluent has yet to be thoroughly investigated. As a result, the maximum specific biogas production $(p<0.05)$ was achieved with T5 (18 mg/L Fe NP) with a value of $136.74 \mathrm{l} / \mathrm{g}$ VS and specific methane production enhanced by $64.5 \%(p<0.05)$ as compared to cattle manure alone. 


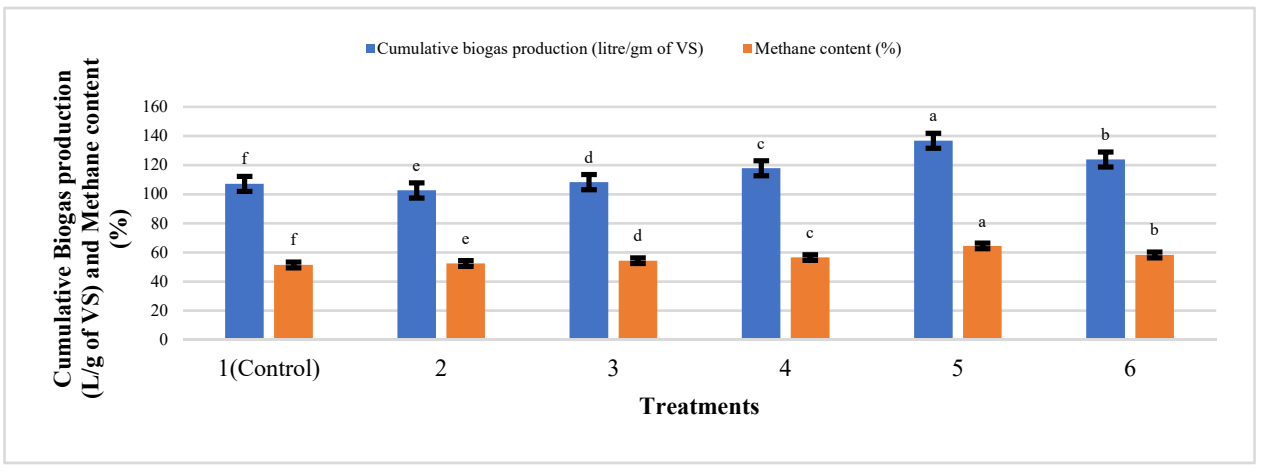

Figure 8. Cumulative biogas and methane production from cattle manure supplemented with different concentrations of IONPs. Bars with different letters depict significantly different values at $p \leq 0.05$.

\subsection{Changes in Physicochemical Properties during Anaerobic Digestion of Cattle Manure}

The anaerobic digestion of cattle dung supplemented with different treatments was tested for various parameters such as $\mathrm{pH}$, TVFA, TS, VS, organic carbon, and dehydrogenase activity at the laboratory scale. The variations in $\mathrm{pH}$ during the anaerobic digestion of cattle dung are shown in Figure 9.

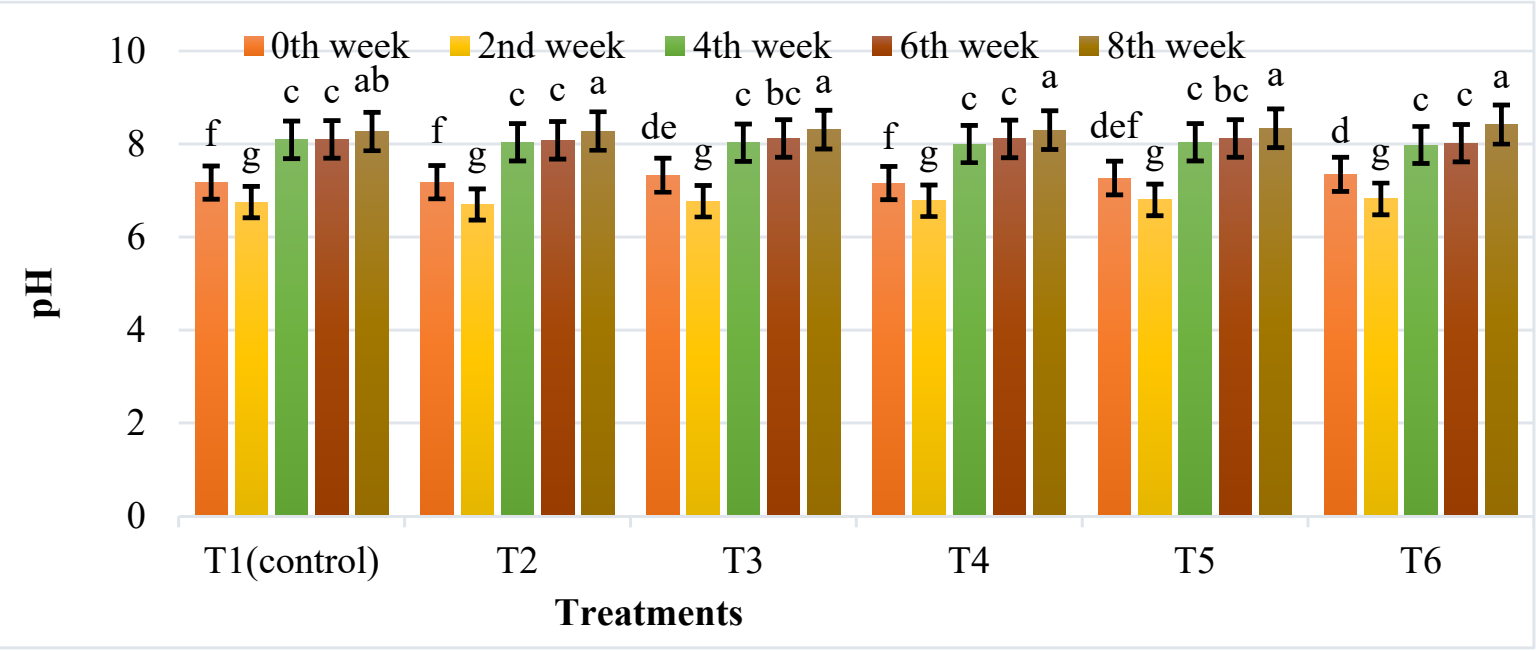

Figure 9. The effects of different IONPs treatments on the $\mathrm{pH}$ value of cattle manure during anaerobic digestion. Bars with different letters depict significantly different values at $p \leq 0.05$.

In the first two weeks, the $\mathrm{pH}$ value of each bio-digester rapidly decreased from 7.35 to 6.70, which may be due to the corrosion of IONPs generating $\mathrm{OH}^{-}$, thereby increasing the buffering capacity, which led to an increase in $\mathrm{pH}$ of all bio-digesters after eight weeks. T5 had the highest TVFA content $(980 \mathrm{mg} / \mathrm{kg}$ ) and T2 had the lowest (345 mg/kg) (Figure 10).

When the amount of TVFAs in the biogas was greater than $980 \mathrm{mg} / \mathrm{kg}$, the digestion process was stopped. After treatment with IONPs, the total volatile fatty acid (TVFA) content did not vary significantly from that of the control. As shown in Figure 10, the TVFA ranged from 280 to $980 \mathrm{mg} / \mathrm{kg}$, indicating that microbial activities were harmonized. The organic carbon varied from 42.52 to $48.14 \%$ in different treatments, and the maximum was found to be $48.14 \%$ in T2 (Figure 11). Maximum TS and VS were also found to be $19.15 \%$ and $87.0 \%$ in T2 (Table 2). 


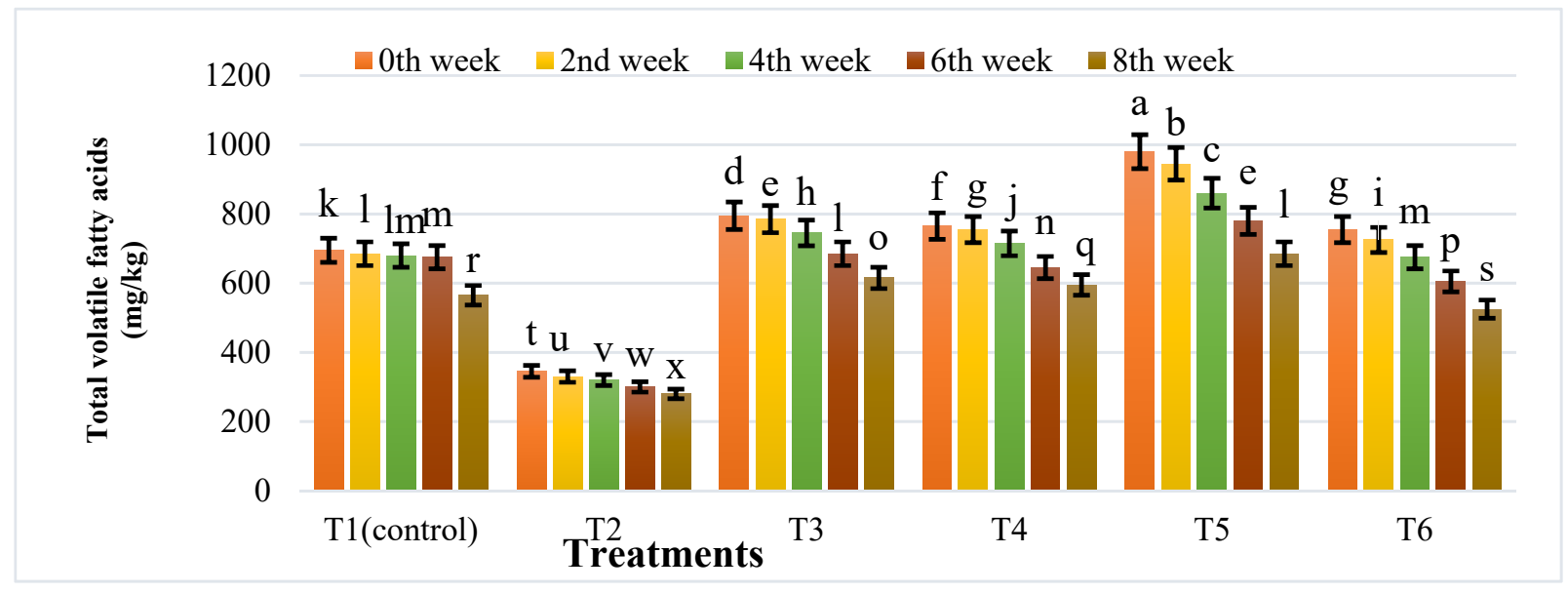

Figure 10. Effects of different treatments of IONPs on TVFA value during anaerobic digestion of cattle manure. Bars with different letters indicate significant differences $(p \leq 0.05)$ between treatments.

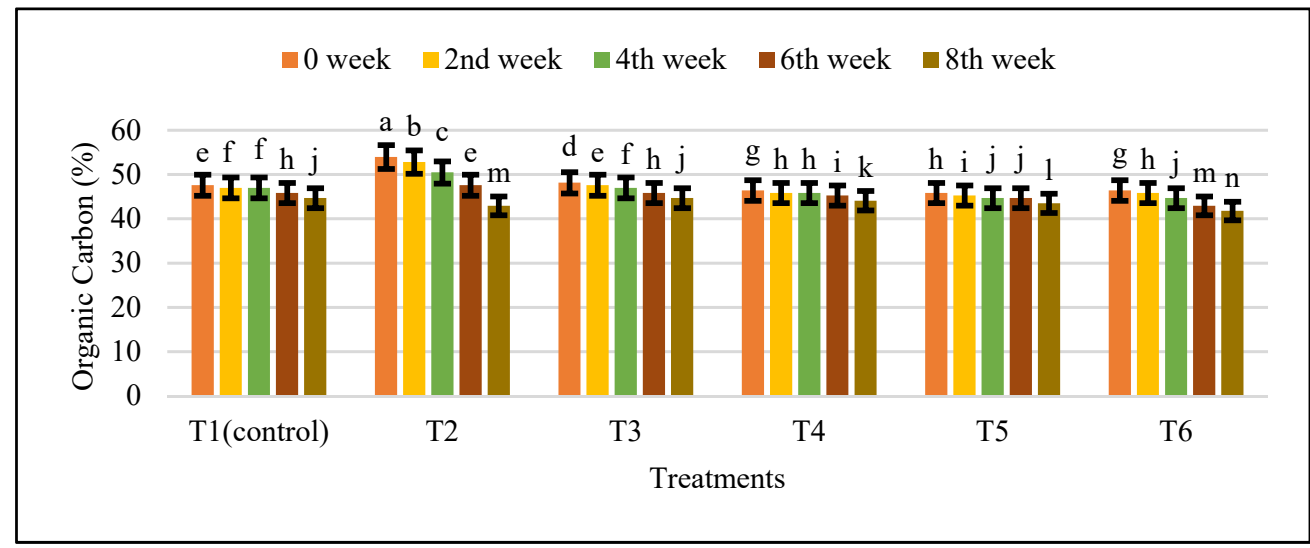

Figure 11. The effects of different treatments of IONPs on organic carbon content during anaerobic. digestion of cattle manure. Bars with different letters depict significantly different values at $p \leq 0.05$.

Table 2. Effect of different treatments of IONPs on total solids and volatile solid degradation during eight weeks of batch digestion.

\begin{tabular}{ccccccccccc}
\hline Time (Weeks) & 1st & & 2nd & & 4th & & 6th & \multicolumn{1}{c}{ 8th } \\
\hline Treatments/Parameters (\%) & TS & VS & TS & VS & TS & VS & TS & VS & TS & VS \\
\hline T1 & 18.42 & 82.0 & 17.80 & 81.0 & 16.90 & 80.0 & 15.4 & 79.0 & 14.15 & 78.0 \\
\hline T2 & 19.15 & 83.0 & 18.70 & 11.0 & 17.65 & 87.0 & 15.23 & 82.0 & 13.41 & 74.0 \\
\hline T3 & 18.73 & 82.3 & 17.88 & 82.0 & 16.25 & 81.0 & 14.10 & 80.0 & 12.70 & 77.0 \\
\hline T4 & 17.65 & 80.0 & 16.44 & 79.0 & 15.51 & 79.0 & 13.96 & 78.0 & 12.27 & 76.0 \\
\hline T5 & 17.83 & 79.0 & 16.77 & 78.0 & 15.03 & 77.0 & 12.50 & 77.0 & 10.14 & 75.0 \\
\hline T6 & 18.15 & 81.0 & 16.25 & 80.0 & 15.09 & 78.0 & 13.85 & 74.0 & 11.28 & 72.0 \\
\hline
\end{tabular}

The increase was due to higher microbial activity caused by the availability of nutrients leading to greater degradation of solids and, consequently, higher biogas yield. Zupancic et al. [39] observed that a 10\% increase in volatile suspended solids degradation efficiency was reported when household organic waste was co-digested with municipal sludge. The maximum degradation of TS (43.1\%) and VS (7.5\%) was observed in T5 and T6 after the 8th week of digestion (Figure 12), which is better as compared with earlier studies. 


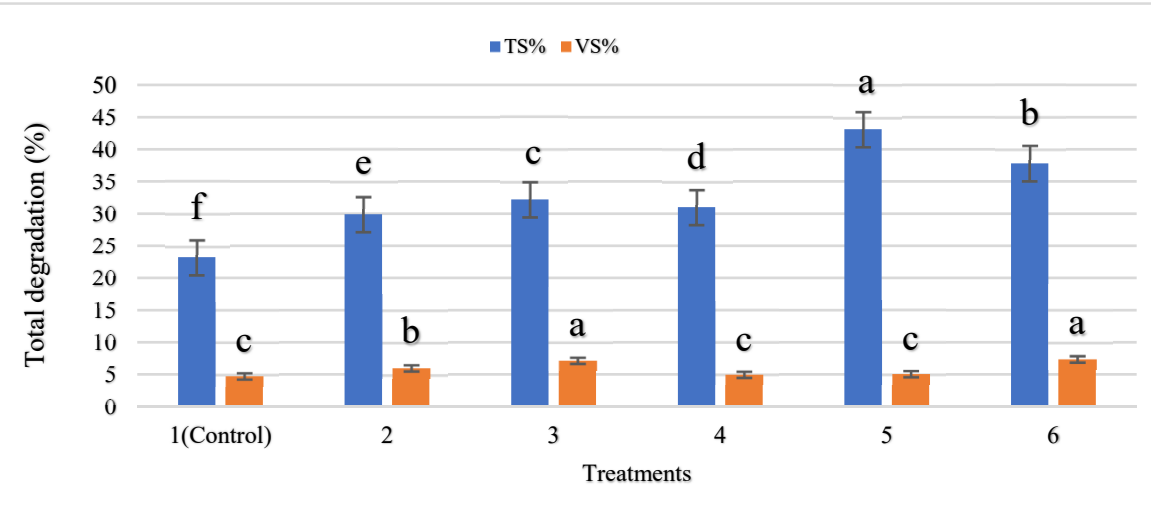

Figure 12. Degradation of total solids (TS) and volatile solids (VS) during anaerobic digestion. Bars with different letters depict significantly different values at $p \leq 0.05$.

Changes in volatile solids content with the addition of IONPs resulted in increased organic matter decomposition, which contributed to the differences in methane outputs. When the cattle manure was treated with $18 \mathrm{mg} / \mathrm{L}$ IONPs (T5), the maximum TS degradation was seen, followed by $21 \mathrm{mg} / \mathrm{L}$ IONPs (T6), resulting in removal rates of 43.1 and $7.5 \%$, respectively. These findings were in accordance with those of Abdelsalam et al. [19], who found that increasing the number of metallic nanoparticles added to cattle slurry biodigesters and enhanced biogas and methane output. After the completion of eight weeks of batch anaerobic digestion of cattle manure, the $\mathrm{pH}$ was increased and other parameters (TVFA, TS, VS, OC) decreased in all treatments.

Dehydrogenase activity (microbial biomass) was also determined at 15-day intervals for eight weeks in a batch digestion manner. The dehydrogenase activity was increased from 1180 to 1436,1275 to 1518,1305 to 1687,1295 to 1596,1165 to 1344 , and 1055 to $1335 \mathrm{~g} \mathrm{TPF} / \mathrm{g}$ sample/24 $\mathrm{h}$ up to the fourth week during batch digestion in treatments T1 to T6, respectively, and decreased afterwards. The maximum dehydrogenase activity was found in T3 (1305) and increased (1687) up to the fourth week, after which we observed a decrease in the dehydrogenase activity of all the treatments up to the eighth week (Figure 13).

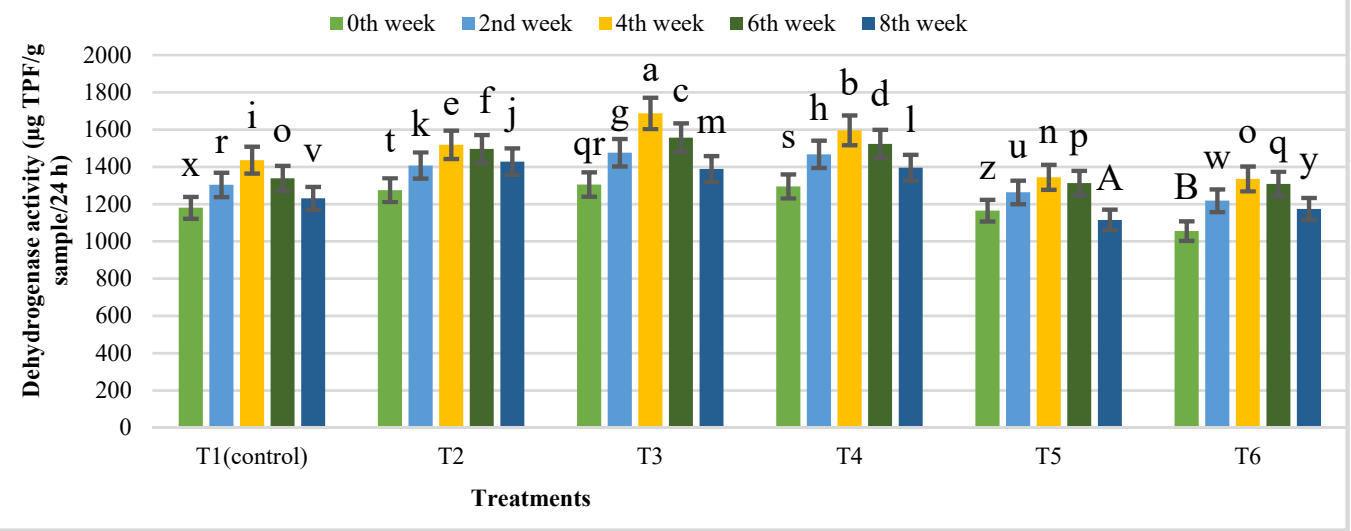

Figure 13. Dehydrogenase activity of different treatments of IONPs during the anaerobic digestion of cattle manure after eight weeks. Bars with different letters depict significantly different values at $p \leq 0.05$.

After eight weeks of investigation, it was observed that the $18 \mathrm{mg} / \mathrm{L}$ IONPs (T5) treated bio-digester produced adequate amounts of biogas and methane when compared to the control, exhibiting good utilization of acetic, propionic, formic, and butyric acids. Because FeNPs accelerate the transfer of electrons from acetogens to methanogens as an 
energy source, the conversion of TVFAs to methane was increased. Noonari et al. [40] studied the influence of $\mathrm{Fe}_{3} \mathrm{O}_{4}$ nanoparticles on methane yield in the anaerobic co-digestion of canola straw and banana plant wastes with buffalo dung and found promising results.

\section{Conclusions}

This study reported on the successful use of Azadirachta indica as a green strategy for the synthesis of IONPs. As a result, IONPs were formed through the development of a black-coloured solution. The rapid reduction process confirmed the efficacy of Azadirachta indica extract as a reducing and stabilizing agent. The spherical shape of IONPs with an average size of $52.5 \mathrm{~nm}$ and an irregular structure was confirmed using TEM imaging. On the other hand, the impact of IONPs on the stability of the AD process of cattle manure and the chemical composition of the effluent was examined. Five different concentrations of IONPs were applied to a lab-scale batch bio-digester. The results revealed that cumulative biogas and methane yields with the addition of IONPs (18 mg/L) as a supplement reached $136.74 \mathrm{~L} / \mathrm{g}$ VS and $64.5 \%$, respectively, which were $27.6 \%$ (biogas) and $25.4 \%$ (methane) greater than the corresponding values of the control group after the eighth week of digestion.

Author Contributions: Conceptualization, K.M. (Kamla Malik), D.S. and M.S.; methodology, K.M. (Kamla Malik) and D.S.; validation, K.M. (Kamla Malik), M.S., P.R., S.M. (Shikha Mehta) and N.K.; software, D.S., formal analysis, D.S., K.M. (Kamla Malik) and N.A.; investigation, K.M.; resources, D.S., K.M. (Kamla Malik) and D.S.; data curation, D.S., M.S., N.K. and K.M. (Kamla Malik),; writingoriginal draft, K.M. (Kamla Malik); writing—review and editing, K.M. (Kamla Malik); M.S., D.S., V.R., K.M. (Karmal Malik) and N.D.; visualization, D.S. and K.M. (Kamla Malik); supervision, K.M. (Kamla Malik); funding acquisition, D.S., K.M. (Kamla Malik), M.S., N.K., P.R., S.M. (Shikha Mehta), V.R., K.S., K.M. (Karmal Malik), S.M. (Shweta Malik), N.D. and N.A. All authors have read and agreed to the published version of the manuscript.

Funding: This research was supported by scheme ICAR-9-Micro at the Department of Microbiology, CCS Haryana Agricultural University, Hisar, India.

Institutional Review Board Statement: Not applicable.

Informed Consent Statement: Not applicable.

Data Availability Statement: The data used for the analysis in this study are available within the article, while the datasets used or analysed during the current study are available from the corresponding author upon reasonable request.

Acknowledgments: The author is thankful to HOD, Department of Microbiology, College of Basic Sciences and Humanities, CCS Haryana Agricultural University, Hisar, for providing the necessary facilities throughout his research work.

Conflicts of Interest: The authors declare no conflict of interest.

\section{References}

1. Meegoda, J.N.; Li, B.; Patel, K.; Wang, L.B. A review of the processes, parameters, and optimization of anaerobic digestion. Int. J. Environ. Res. Public Health 2018, 15, 2224. [CrossRef] [PubMed]

2. Feng, Y.; Zhang, Y.; Quan, X.; Chen, S. Enhanced anaerobic digestion of waste activated sludge digestion by the addition of zero valent iron. Water Res. 2014, 52, 242-250. [CrossRef] [PubMed]

3. Li, Y.; Zhao, J.; Krooneman, J.; Gert, J.; Willem, E. Strategies to boost anaerobic digestion of cow manure: Laboratory achievement and their full-scale application potential. Sci. Total Environ. 2021, 755, 142940. [CrossRef] [PubMed]

4. Romero-Güiza, M.; Vila, J.; Mata-Alvarez, J.; Chimenos, J.; Astals, S. The role of additives on anaerobic digestion: A review. Renew. Sustain. Energy Rev. 2016, 58, 1486-1499. [CrossRef]

5. Ajay, C.M.; Mohan, S.; Dinesha, P.; Rosen, M.A. Review of impact of nanoparticle additives on anaerobic digestion and methane generation. Fuel 2020, 277, 118234. [CrossRef]

6. Mody, V.; Siwale, R.; Singh, A.; Mody, H.R. Introduction to metallic nanoparticles. J. Pharm. Bioallied Sci. 2010, 2, 282-289. [CrossRef]

7. Kamla, M.; Sushil, A.; Karmal, M. Nanotecology: A sustainable solution for bioenergy and biofuel production. J. Nanosci. Nanotechnol. 2021, 21, 3481-3494. [CrossRef] 
8. Machado, S.; Pinto, S.L.; Grosso, J.P.; Nouws, H.P.A.; Albergaria, J.T.; Delerue-Matos, C. Green production of zero-valent iron nanoparticles using tree leaf extracts. Sci. Total Environ. 2013, 445, 1-8. [CrossRef]

9. Abdelsalam, M.; Samer, Y.A.; Attia, M.A.; Abdel-Hadi, H.E.; Hassan, Y.; Badr, Y. Comparison of nanoparticles effects on biogas and methane production from anaerobic digestion of cattle dung slurry. Renew. Energy 2016, 87, 592-598. [CrossRef]

10. Gupta, S.C.; Prasad, S.; Tyagi, A.K.; Kunnumakkara, A.B.; Aggarwal, B.B. Neem (Azadirachta indica): An Indian traditional panacea with modern molecular basis. Phytomedicine 2017, 34, 14-20. [CrossRef]

11. Zambri, N.D.S.; Taib, N.I.; Latif, F.A.; Mohammed, Z. Utilization of neem leaf extract on biosynthesis of iron oxide nanoparticles Molecules 2019, 24, 3803. [CrossRef] [PubMed]

12. Srivastava, S.K.; Agrawal, B.; Kumar, A.; Pandey, A. Phytochemicals of Azadirachta indica source of active medicinal constituent used for cure of various diseases: A Review. J. Sci. Res. 2020, 64, 385-390. [CrossRef]

13. Saleem, S.; Muhammad, G.; Hussain, M.A.; Bukhari, S.N.A. A comprehensive review of phytochemical profile, bioactive for pharmaceuticals and pharmacological attributes of Azadirachta indica. Phytother. Res. 2018, 32, 1241-1272. [CrossRef]

14. Linton, Y.M.; Nisbet, A.J.; Mordue, A.J. The effects of azadirachtin on the testes of the desert locust, Schistocerca gregaria (Forskål). J. Insect Physiol. 1997, 43, 1077-1084. [CrossRef]

15. Chutulo, E.C.; Chalannavar, R.K. Endophytic mycoflora and their bioactive compounds from Azadirachta indica: A comprehensive review. J. Fungi 2018, 4, 42. [CrossRef] [PubMed]

16. Nisbet, A.J.; Mordue, A.J.; Grossman, R.B.; Jennens, L.; Ley, S.V.; Mordue, W. Characterization of azadirachtin binding to Sf9 nuclei in vitro. Arch. Insect. Biochem. Physiol. 2001, 46, 78-86. [CrossRef]

17. Tabatabaei, M.; Aghbashlo, M.; Valijanian, E.; Panahi, H.K.S.; Nizami, A.S.; Ghanavati, H.; Sulaiman, A.; Mirmohamadsadeghi, S.; Karimi, K. A comprehensive review on recent biological innovations to improve biogas production, part 2: Mainstream and downstream strategies. Renew. Energy 2020, 146, 1392-1407. [CrossRef]

18. Ambuchi, J.J.; Zhang, Z.; Feng, Y. Biogas enhancement using iron oxide nanoparticles and multi-wall carbon nanotubes. Int. J. Chem. Mol. Nucl. Mat. Metall. Eng. 2016, 10, 1239-1246.

19. Abdelsalam, E.; Samer, M.; Attia, Y.A.; Abdel-Hadi, M.A.; Hassan, H.E.; Badr, Y. Influence of zero valent iron nanoparticles and magnetic iron oxide nanoparticles on biogas and methane production from anaerobic digestion of manure. Energy 2017, 120, 842-853. [CrossRef]

20. Casals, E.; Barrena, R.; García, A.; González, E.; Delgado, L.; Busquets-Fité, M.; Font, X.; Arbiol, J.; Glatzel, P.; Kvashnina, K.; et al Programmed iron oxide nanoparticles disintegration in anaerobic digesters boosts biogas production. Small 2014, 10, 2801-2808. [CrossRef]

21. Farghali, M.; Andriamanohiarisoamanana, F.J.; Ahmed, M.M.; Kotb, S.; Yamashiro, T.; Iwasaki, M.; Umetsu, K. Impacts of iron oxide and titanium dioxide nanoparticles on biogas production: Hydrogen sulfide mitigation, process stability, and prospective challenges. J. Environ. Manag. 2019, 240, 160-167. [CrossRef] [PubMed]

22. Bhavika, T.; Paras, T. Green synthesis of zero valent iron nanoparticles from Coriandrum sativum and its application in reduction chemical oxygen demand and biological oxygen demand in waste water. South-Asian J. Multidiscip. Stud. 2017, 6, 132-139.

23. Bibi, I.; Nazar, N.; Ata, S.; Sultan, M.; Ali, A.; Abbas, A.; Jilani, K.; Kamal, S.; Sarim, F.M.; Khan, M.I.; et al. Green synthesis of iron oxide nanoparticles using pomegranate seeds extract and photocatalytic activity evaluation for the degradation of textile dye. J. Mater. Res. Technol. 2019, 8, 6115-6124. [CrossRef]

24. Sharma, A.K.; Pawar, C.A.; Prasad, N.R.; Yewale, M.A.; Kamble, D.B. Antimicrobial efficacy of green synthesized iron oxide nanoparticles. Mater. Res. Express 2018, 5, 075402. [CrossRef]

25. Horwitz, W. Official Methods of Analysis of the Association of Official Analytical Chemists; The Association of Official Analytical Chemists: Washington, DC, USA, 2000.

26. Casida, L.E., Jr.; Klein, D.A.; Santoro, T. Soil dehydrogenase activity. Soil Sci. 1964, 98, 371-376. [CrossRef]

27. Christensen, L.; Vivekanandhan, S.; Misra, M.; Mohanty, A.K. Biosynthesis of silver nanoparticles using Murraya koenigii (curry leaf): An investigation on the effect of broth concentration in reduction mechanism and particle size. Adv. Mat. Lett. 2011, 2, 429-434. [CrossRef]

28. Verma, A.; Mehata, M.S. Controllable synthesis of silver nanoparticles using Neem leaves and their antimicrobial activity. J. Radiat. Res. Appl. Sci. 2016, 9, 109-115. [CrossRef]

29. Devatha, C.P.; Thalla, A.K.; Katte, S.Y. Green synthesis of iron nanoparticles using different leaf extracts for treatment of domestic waste water. J. Clean. Prod. 2016, 139, 1425-1435. [CrossRef]

30. Singh, J.; Dutta, T.; Kim, K.H.; Rawat, M.; Samddar, P.; Kumar, P. 'Green' synthesis of metals and their oxide nanoparticles: Applications for environmental remediation. J. Nanotechnol. 2018, 16, 84. [CrossRef] [PubMed]

31. Turakhia, B.; Turakhia, P.; Shah, S. Green synthesis of zero valent iron nanoparticles from Spinacia oleracea (spinach) and its application in waste water treatment. J. Adv. Res. Appl. Sci. 2018, 5, 46-51.

32. Kumar, A.; Sawant, K. Encapsulation of exemestane in polycaprolactone nanoparticles: Optimization, characterization, and release kinetics. Cancer Nanotechnol. 2013, 4, 57-71. [CrossRef] [PubMed]

33. Mystrioti, C.; Xanthopoulou, T.D.; Tsakiridis, P.; Papassiopi, N.; Xenidis, A. Comparative evaluation of five plant extracts and juices for nano-iron synthesis and application for hexavalent chromium reduction. Sci. Total Environ. 2016, 539, 105-113. [CrossRef] [PubMed] 
34. Yazdani, M.; Ebrahimi-Nik, M.; Heidari, A.; Abbaspour-Fard, M.H. Improvement of biogas production from slaughterhouse wastewater using biosynthesized iron nanoparticles from water treatment sludge. Renew. Energy 2019, 135, 496-501. [CrossRef]

35. Yang, Y.; Guo, J.; Hu, Z. Impact of nano zero valent iron (NZVI) on methanogenic activity and population dynamics in anaerobic digestion. Water Res. 2013, 47, 6790-6800. [CrossRef] [PubMed]

36. Hijazi, O.; Abdelsalam, E.; Samer, M.; Attia, Y.A.; Amer, B.M.A.; Amer, M.A.; Badr, M.; Bernhardt, H. Life cycle assessment of the use of nanomaterials in biogas production from anaerobic digestion of manure. Renew. Energy 2020, 148, 417-424. [CrossRef]

37. Men, Y.; Zheng, L.; Zhang, L.; Li, Z.; Wang, X.; Zhou, X.; Cheng, S.; Bao, W. Effect of adding zero valent iron on the anaerobic digestion of cow manure and lignocellulose. Front. Bioeng. Biotechnol. 2020, 28, 590200. [CrossRef]

38. Emmanuel Kweinor, T.; Amo-Duodu, G.; Rathilal, S. Synergistic effects of magnetic nanomaterials on post-digestate for biogas production. Molecules 2020, 26, 6434. [CrossRef]

39. Zupančič, G.D.; Uranjek-Ževart, N.; Roš, M. Full-scale anaerobic co-digestion of organic waste and municipal sludge. Biomass Bioenergy 2008, 32, 162-167. [CrossRef]

40. Noonari, A.A.; Mahar, R.B.; Sahito, A.R.; Brohi, K.M. Anaerobic co-digestion of canola straw and banana plant wastes with buffalo dung: Effect of $\mathrm{Fe}_{3} \mathrm{O}_{4}$ nanoparticles on methane yield. Renew. Energy 2019, 133, 1046-1054. [CrossRef] 